This is the accepted version of the article cited here:

Dressler, R. (2015). Signgeist: Promoting bilingualism through the linguistic landscape of school signage. International Journal of Multilingualism, 12(1), 128-145, doi:10.1080/14790718.2014.912282

\title{
Signgeist: Promoting bilingualism through the linguistic landscape of school signage
}

\section{Abstract}

This study is an examination of signage and sign making practices in one elementary (Kindergarten - grade six) public school which offers a German Bilingual Program for the development of German-English bilingualism. Schools are public spaces in which the visible language choice on signs reveals the circulating discourses around language status. Surprisingly, little is known about the creation of these signs and the decision making behind their creation. This linguistic landscape is analysed using nexus analysis (Hult, 2009) which sheds light on the convergence of a) the historical body of social actors in which teachers are primarily responsible for sign making b) an interaction order in which teachers practice organic sign placement, and c) discourses in place which include the promotion of bilingualism. This research reveals that signage is limited in its promotion of German-English bilingualism, constrained strongly by practices that define sign maker's responsibility and the German Bilingual Program's reach. This study contributes to our understanding of linguistic landscape research by exploring the degree to which a school offering a Bilingual Program promotes bilingualism through signage. Educators and researchers looking critically at school signs are given cause to question accepted practices and strong discourses which limit the promotion of bilingualism.

Keywords: linguistic landscape; bilingual program; signage; nexus analysis; German; bilingualism

Word Count: 6692 


\section{Introduction}

This linguistic landscape analysis (Gorter, 2006) of one German Bilingual Program (GBP) reveals constraints upon sign making practices that affect the promotion of German-English bilingualism. Schools are public spaces wherein displays of language can inform our understanding of the discourses around language status or use (Cummins, 2005; Shohamy, 2006). While 'a dominant ideology that positions the majority language (often English) as the only language of communication' is 'constantly produced and reproduced' in mainstream schools (Blackledge \& Creese, 2010, p. 27), schools offering bilingual education have, by virtue of their purpose, opportunities to construct a bilingual/multilingual space via signage.

Little research has been done on sign making practices as a means for promoting bilingualism. Teachers create signs that add to the language input they provide through instruction (Brown, 2012; Morgan, 2004) and administrators place signs as part of their marketing to the general public (Eaton, 2005). Sign making practices provide environmental print seen by students (Giles \& Tunks, 2010; Prior, 2009; Reyes \& Azuara, 2008). While bilingual signs would serve the purpose of promoting bilingualism, a nexus analysis of sign making in this Program sheds light on practices that compartmentalize sign making according to the responsibilities of the sign maker and impede the reach of the Bilingual Program.

The purpose of this study is to reveal the degree to which signs promote bilingualism in a school program in which the promotion of bilingualism is seen as a natural outcome of its goal of providing language instruction in two languages (Wu \& Bilash, 2000). This is accomplished through nexus analysis (Scollon \& Scollon, 2004) which provides a holistic framework for investigation. This study contributes to the field of linguistic landscape research by shedding light upon the complexities of linguistic landscape research in schools. 


\section{Sign making practices in schools}

In elementary schools, signs make up part of the environmental print: the 'symbols all around' (Prior, 2009, p. 9). This environmental print can facilitate early writing and reading by providing early success and exemplars for copying (Reyes \& Azuara, 2008). Recognizing this, teachers seek out or create signs that provide language input for their students. Where these signs occur in more than one language, they serve to promote bilingualism through their support of biliteracy.

Teachers use environmental print to draw students' attention to language and increase their language awareness. The classroom is an extension of the world that school children see around them (Giles \& Tunks, 2010). As such, the signs that they encounter are among their first 'concrete exposures to written language' (p. 23), which they then go on to read even before learning to read print in books. Through the creation of 'homemade environmental print' (i.e., signs for the classroom), teachers add to the 'commercial environmental print' to which students are already accustomed (Giles \& Tunks, 2010, p. 25). This exposure to print is beneficial to the early literacy of all children, regardless of home language (p. 23).

In examining the ability to read and write in two languages (i.e., biliteracy), Reyes and Azuara (2008) examine the relationship between this emerging biliteracy and one's environment, as bilingual children negotiate two languages in the different contexts of home, school and neighbourhood. In some cases, children see signage in their home language in their neighbourhood, but not at school (Moore, 2010), but where the bilingualism is a goal of the classroom, teachers purposefully provide environmental print in both languages (Brown, 2012). Where students are included in the creation of this 'vernacular' environmental print (Brown, 2012, p. 291), their biliteracy is supported (Cummins \& Early, 2011). In this way, the sign making practices of teachers and their students result in environmental print that promotes bilingualism. 
While the above research shows the implications of the use of environmental print in the form of bilingual signs, the specific contexts in which they are found bring with them discourses that may not encourage these sign making practices. What follows is an overview of Bilingual Programs in western Canada and the specific historical, political and pedagogical discourses that shape this social context and situate them as an important linguistic landscape for investigation.

\section{Bilingual programs in western Canada}

Bilingual education in Canada comprises Immersion programs in one of two official languages (i.e., English or French) and Bilingual Programs in minority languages in western Canada. Of these, French Immersion programs, which offer 100\% instruction in the target language at the elementary school (Kindergarten to sixth grade ${ }^{1}$ ) level, are best known and most widely studied (Genesee \& Gándara, 1999; Swain \& Lapkin, 2005). Bilingual Programs offer instruction in a minority language for up to $50 \%$ of the school day at the elementary school level (Tavares, 2000). The German Bilingual Program's unique historical background justifies this particular inquiry into the linguistic landscape of a school.

At present, most Bilingual Programs are centred in urban areas, under the discretion of the local school division, where parents have petitioned the public ${ }^{2}$ school jurisdiction and numbers warrant. In addition to languages of more established immigrant groups (e.g., Ukrainian and German) and indigenous languages (e.g., Cree), languages of newer immigrant groups have been added in the last decade (e.g., Mandarin, Spanish, Punjabi). German Bilingual Programs are uniquely positioned. They are the most numerous of the original programs (e.g., Ukrainian, Hebrew) and are also not geographically limited as some of the newer programs are (e.g., Spanish). 
In light of this positioning as an established program across western Canada, the choice of a German Bilingual Program as a site of inquiry into the sign making practices of a Bilingual Program allows the examination of an established interaction order (the ways of doing), established and evolving discourses (ways of thinking) and experienced social actors (ways of being). This examination, viewed holistically, reveals the nexus of practice around sign making in a Bilingual Program.

\section{The linguistic landscape of a school}

Linguistic landscape is defined as the language on signage 'of a given territory, region, or urban agglomeration' (Landry \& Bourhis, 1997, p. 25). Previous linguistic landscape research has focussed on signage within a city (Boudreau \& Dubois, 2005; Curtin, 2009, Lai, 2013), neighbourhoods (Boudreau \& Dubois, 2005; Cenoz \& Gorter, 2006) or geographic areas (Pietikäinen, Lane, Salo, \& Laihiala-Kankainen, 2011), noting how the signs of a setting reflect and inform the language use of a given area. Yet, as linguistic landscape research develops further, investigations are beginning to include schools (Brown, 2012; Dagenais, Moore, Sabatier, Lamarre, \& Armand, 2008; Sayer, 2009) and incorporate new methodologies such as nexus analysis (Pietikäinen \& Kelly-Holmes, 2011). This study provides an investigation of a unique school setting, a German Bilingual Program in western Canada, which goes beyond the traditional analysis of signage to include a holistic look at the creation, purpose and use of signs with input from the sign makers themselves.

Researchers of linguistic landscapes (Boudreau \& Dubois, 2005; Cenoz \& Gorter, 2006, 2008; Gorter, 2006; Shohamy \& Waksman, 2009) are interested in how signs convey messages to the reader about the societal attitude toward each language and the purpose(s) they serve in the community (e.g., language of prestige, necessity, dominance). Specifically, they examine signs 
by noting the order of languages, type of font, use of translation or placement of languages on the signs. They distinguish between top-down signs, official signs subject to government and policy regulations and bottom-up signs, unofficial signs posted by individuals (Gorter, 2006, p. 3). Interpreting these data, researchers draw conclusions about societal language messages; however, missing from the research is input from the sign makers themselves regarding the content and function the signs serve.

Observing this omission, Hult (2009) argues for a means of holistic inquiry into the linguistic landscape of a given setting through the union of two methodologies: linguistic landscape analysis and nexus analysis (Scollon \& Scollon, 2004). Viewed through an ecology of languages framework (Kramsch \& Steffensen, 2008), nexus analysis allows researchers to investigate the human actions behind the linguistic landscape. While linguistic landscape analysis uses photography and visual analysis to determine the nature of signage (i.e., top-down, bottom-up), languages used and their relationship to each other (e.g., translation or not, font size, order), nexus analysis provides 'a systematic way of interpreting data about the distribution of languages in public spaces' (p. 90). This investigation is accomplished by examining the convergence or nexus of practice of the ways of thinking (discourses in place), ways of doing (interaction order) and ways of being (historical body). In other words, sign making practices can be better understood by seeking out the sign makers or those who understand their decisionmaking (i.e., historical body) and learning about the location-specific practices (i.e., interaction order) and discourses (discourses in place). Nexus analysis allows the researcher to see how a social practice, in this case, the promotion of bilingualism, comes together in a nexus of practice that is shaped by the three aspects (i.e., historical body, interaction order and discourses in place). Nexus analysis permits the researcher to "pay attention to several dimensions of 
multilingualism at the same time' (Hult, 2009, p. 88), a useful tool for a study of the unique nature of signage in schools.

Shohamy (2006) lists schools along with cities and neighbourhoods among the public spaces where the language use on signs communicates important messages about 'de facto policy and practice' (p. 110). Like neighbourhoods and cities, schools are subject to decision-making surrounding what signs can be displayed and practices which determine who can put up signs and for what purposes. Some researchers (Brown, 2012; Dagenais, et al., 2008; Sayer, 2009) are beginning to see how linguistic landscape analysis can be used in educational settings to provide insight into schools as sites where languages come together, but where 'the texts most visible in [the students'] particular environment do not necessarily reflect the local language practices' (Dagenais, et al., 2008, p. 257). However, in their own research, some of these researchers (Dagenais, et al., 2008; Sayer, 2009) have limited their analyses to the neighbourhoods surrounding the school, neglecting the environment in which the students spend the most time: the schools themselves. This lack of school-specific research reinforces the need to investigate the school context itself.

Within a school, language on signs serves a number of functions (Halliday, 1969). Regulatory signs direct the actions and behaviours of the social actors (e.g., "No Smoking"; "Reserved Parking Day \& Night"). Interactional signs draw upon the relationship between the invisible sign maker and the reader, often eliciting a particular behaviour or conveying information through a sense of common purpose (e.g., "Save the World"; "We Have the Right to Choose Our Friends"). Some signs serve a personal function, emphasizing individuality by raising some individuals above others or promoting behaviour that leads to success (e.g., "Read to Succeed"; "Good Readers ... "). Other signs have an imaginative function. These can take the 
form of inspirational quotes ("You are about to enter the learning zone"), travel posters, or decorations. Still others are representational, providing location labels, even when those might be superfluous ("Main Doors"; "In/Out"). None of the signs in this context fulfilled an instrumental or heuristic function. The distribution of these signs and the languages chosen to serve these functions shed light upon the sign makers' purposes in creating and placing the signs.

The linguistic landscape of a Bilingual Program can then be understood to consist of the signs on the school grounds and within the school which contribute to the environmental print (i.e., linguistic input in two languages) and serve specific functions. While the school is 'most often perceived by passers-by as one structured place' (Hult, 2009, p. 94), in actuality this study reveals that the social actors who create signs within the school are numerous and are influenced by many discourses. Examining signs of a Bilingual Program documents language usage in the Program and reveals the role of signage in schools. By investigating the linguistic landscape using nexus analysis, this study reveals the degree to which signs promote bilingualism within the Bilingual Program.

\section{Methodology}

The following research question guided this study: how do the sign making practices of teachers in a German Bilingual Program promote bilingualism?

Since Bilingual Programs have bilingualism as one of their educational goals (Wu \& Bilash, 2000), the linguistic landscape promotes the bilingual nature of the program if it contains both languages for communicative purposes aimed at students. In addition, this bilingual language usage promotes the image of the school as a bilingual space through bottom-up and top-down signage from various sign makers aimed at parents of potential students, as well as the general public. 


\section{Setting}

The specific focus of this study is a Bilingual Program in Alberta, a province in western Canada. Of the available minority language Bilingual Programs (e.g., Ukrainian, Spanish, Punjabi), the German Bilingual Program is one of the oldest and most geographically-spread with a total of eleven schools in four urban centres: Winnipeg, Edmonton, Sherwood Park and Calgary. The German Bilingual Program in this study is located in a Kindergarten to grade six, dual-track elementary school in an urban centre in western Canada. The school had just over 300 students during the academic year of the study, of which approximately half were students in the German Bilingual Program and the other half were in an English-medium program. The students from both programs share a gymnasium, lunch room, music room, library, entrance and main hallways. The classrooms for the German Bilingual Program are located in a separate wing from the English-medium Program. As a result, the children from both programs rarely enter the wing of the program they are not enrolled in. Only the signs in the common areas and German Bilingual Program wing are readily viewed by all German Bilingual Program students. That is to say, these students see the signs outside the school, in the main entrance, main corridor, stairwell leading to the German wing and the corridor outside the German Program classrooms.

\section{Procedures}

I received ethics approval from my university IRB and the local school board to document and investigate the linguistic landscape of the school. There was a proviso that the photographs contain no children or identifying information about the school. I photographed all of the signs of the school as they appeared on one day in February of that year. This involved signage on the outside of the school, in the entrance and in the classroom wings of the school and excluded the insides of classrooms, the domain of some, but not all students. This analysis focuses on only those signs that all students in the Bilingual Program are most likely to see, with some 
comparative reference to those in the parallel wing that houses the classrooms belonging to the English-medium Program (EMP).

Once downloaded, the digital photographs were sorted by the name of the area of the school in which they were located using location notes made during the photography session. Signs were first analyzed according as to what language(s) appear on the signs and the categories of top-down or bottom-up signs (Gorter, 2006, p. 3). With regards to language, the photographs were classified as to the languages that appear on them (English only, German only, both English and German, or multilingual). They were classified as top-down if they were official signs of the school board, government or outside agency and bottom-up if the signs were created locally (i.e., in the school). As with all linguistic landscape research, the researcher must decide the demarcation between top-down and bottom-up. I have chosen to differentiate between those signs that are physically created outside of the school and those that are created inside the school. This analysis provided the basis for the creation of a slide show of representative pictures for the focus group of teachers.

The focus group ${ }^{3}$ I conducted with teachers augmented the investigation of the nexus of practice surrounding signage in this setting. Although administrators were also invited, none participated. As such, I had to limit my analysis to data obtained from teachers. My goal was to gain insight into the identity of the sign makers and the people responsible for hanging up the sign (i.e., historical body), how the decision to hang a sign was made (i.e., interaction order), as well as the intended audience and function of the different signs (discourses in place). In some cases, the teachers provided me with their perceptions of why others had hung certain signs, since the sign maker was either no longer on staff or not present in the focus group. Since the 
teachers are informed social actors in this context, the focus group served nexus analysis function of "interactions with members" (Scollon \& Scollon, 2004, p. 158).

I showed the focus group a slide show of a representative sample of signs. They were asked who likely posted the signs and what, if any, deliberate decision making went into the creation of the sign, including the language(s) used and the location of these signs. These questions sparked further discussion among the members of the focus group. I made notes on their discussion. The notes informed the completion of an Excel spreadsheet documenting details about the function of each individual photograph.

The teachers present in the focus group represented the majority of teachers teaching in the German Bilingual Program. Five out of six participants came to Canada as teenagers or adults and all but one took their teacher training in Canada. As a result, they express a high comfort level with both German and English and, although only two have specific second language pedagogical training, all are competent in elementary years' pedagogy. It is important to note that I did not ask them to identify if they personally were responsible for the creation of the sign as I wanted the teachers to speak freely about the signs, their creation and functions. As such, their input regarding the decision making behind signs within the school is a collective voice and provides a "resolution among contradictions" in my initial analysis (Scollon \& Scollon, 2004, p. 158).

This study was part of a larger study in which I visited the school seventeen times over a five month period. Each visit was at least a half day in length. Observations from my visits supplement this analysis. They provided a more complete picture of the nature of signage in this Bilingual Program and allowed me to further classify the signs according to who was 
responsible for choosing to post the sign, how that decision was made, the function and intended audience of particular signs.

The nexus of practice around sign making brings together the historical body, interaction order and discourses in place of the linguistic landscape of the GBP. The historical body of sign makers focuses on the teachers. The interaction order dictates when, where and how orderly the signs are created and placed. The discourses in place influence which signs are made and why, what languages are chosen and any tension among discourses present in this linguistic landscape. The nexus of practice around signage in the German Bilingual Program reveals which signs promote the goals of the school and how the ways of thinking, doing and being behind the GBP's linguistic landscape come together to shape this linguistic landscape.

\section{Nexus of Practice}

An analysis of , the linguistic landscape of the Bilingual Program according to language(s) and category (i.e., top-down/bottom-up) reveals a preference toward English and a strong reliance upon bottom-up signage. An examination of the historical body, interaction order and discourses in place, the latter including the functions of the language within the message (Halliday, 1969), informs our understanding of the nexus of practice. This nexus of practice is constrained by teachers' interpretations of their responsibility and the GBP's reach.

A total of 124 signs containing text ${ }^{4}$ were photographed: 52 in the GBP classroom wing, 34 in the English-medium program classroom wing and 38 in the hallways and entrances common to both programs (i.e., common areas). Since the signs in the EMP were in English only (12 top-down and 22 bottom-up), this analysis considers the languages and categories of the signs in the GBP wing and common areas combined. Of these signs, 68 (75\%) were in Englishonly, $13(14 \%)$ were in German-only, seven ( $8 \%)$ had both languages and three $(3 \%)$ were 
multilingual. Of the 68 English signs, 26 (29\%) were top-down signs and 42 (46\%) were bottomup signs. Of the 13 German-only signs, only two (2\%) were top-down signs with the remaining $11(12 \%)$ being bottom-up signs. Of the seven bilingual (German-English) signs, four (4\%) were top-down signs. The remaining three (3\%) were bottom-up signs. All of the multilingual signs 3 (3\%) were top-down signs. In other words, over half (61\%) of all the signs were bottom-up signs and nearly half of the total signs (46\%) were English-only bottom-up signs. In other words, the majority of signs are bottom-up signs in English and German-only signs outnumber bilingual or multilingual signs combined (Chart 1).

Chart 1 . Sign by language and category

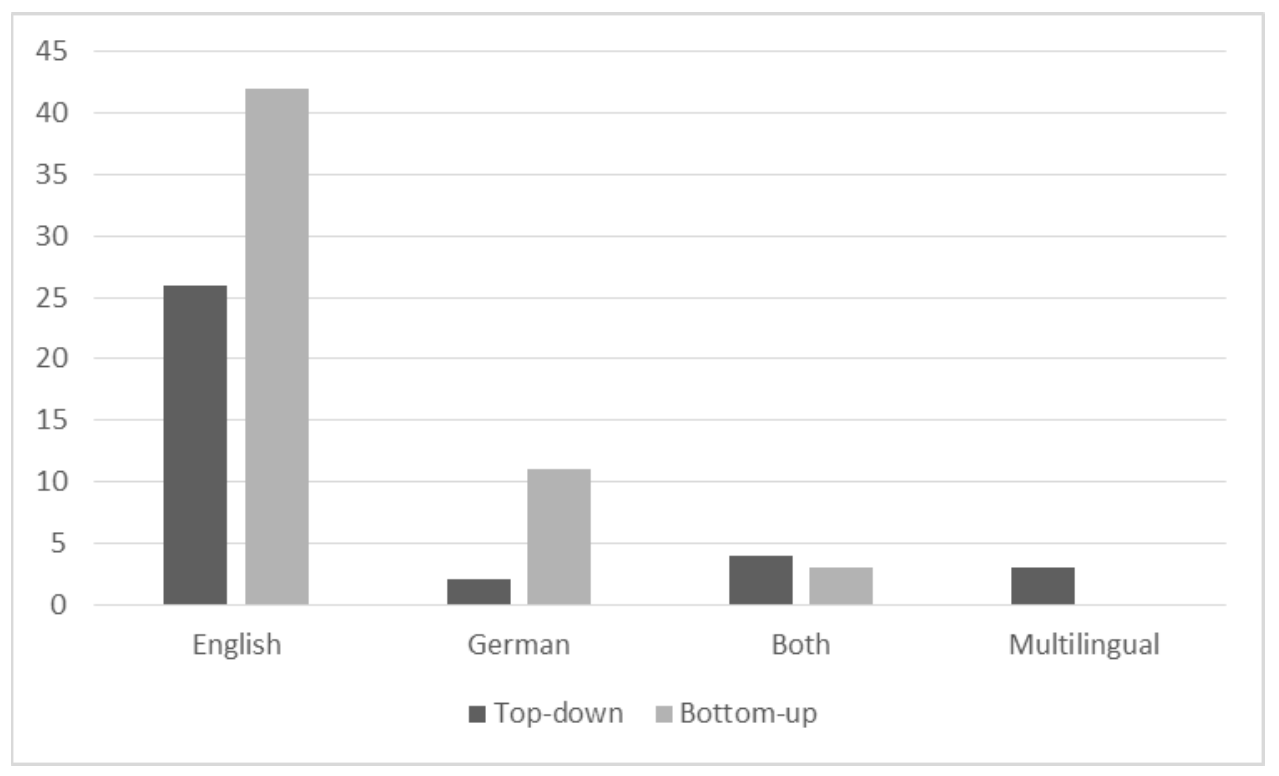

The characteristics of historical body, interaction order and discourses in place specific to this context converge in a nexus of practice of sign making. The focus group of teachers indicated that an important characteristic of the historical body of the German Bilingual Program is the diversity of sign makers and the predominance of teachers as sign makers. Just as the linguistic landscape of a retail street may be characterized by a myriad of shop owners whose signage stands amid graffiti and official city signs (Shohamy, Ben-Rafael, \& Barni, 2010), the 
linguistic landscape of a school is also subject to a variety of individuals, all adding signs to this space. The teachers noted that some signs were placed by the school board in preparation for the opening of the school (Figure 1) and others by the school administrators for the opening of the German Bilingual Program years later (Figure 2). The GBP teachers of the focus group indicated that they are responsible for many of the signs such as German-only signs created by students as class work and displayed by teachers. Of the signs identified by the teachers as being created by the students, the majority are English-only bottom-up signs created for school clubs. Only class work on display appears as German-only signs. Notably, there is no evidence of student-created signs that could be considered uniquely student-generated (e.g., graffiti, signs advertising upcoming personal events (Shohamy, et al., 2010)). The ways of being (i.e., the historical body) of sign makers within the GBP comprises a diverse group of school administrators, teachers and students, in addition to the school board, with teachers currently being the most productive.

The interaction order surrounding the creation and placement of signs in the school is characterised by a coexistence of orderly placement and organic proliferation. Orderly placement is seen in the creation and placement of signs that are common to most western Canadian schools (e. g., signs on washroom doors, maintenance signs). Certain areas of the school are reserved for specific displays, such as the bulletin boards outside teachers' classrooms. In contrast, organic proliferation marks the interaction order of many signs. Teachers freely avail themselves of surfaces other than their designated bulletin board (e.g., doors, walls) and student signs are either strategically places (e.g., 'lights out' signs near light switches) or taped at various heights in randomly-chosen locations ${ }^{5}$. This haphazard placement and the lower quality of the posters suggest that they are temporary and disposable. The coexistence of orderly placement and organic proliferation are characteristics of the ways of doing (i.e., interaction order) of the GBP. 
Discourses in place are revealed in the number of purposes for signs, intended audience and the function of the messages within the signs. Signs aimed at students carry educational message that promote health and fitness, encourage appropriate school behaviour, instruction educational strategies (e.g., reading strategies), or inform as to upcoming events and the identification of locations, including those that are off-limits to them. Some of these same signs are also aimed at parents who might visit the schools, to provide a sense of an educational school culture. While some information on the signs may be redundant (e.g., labelling the main doors as 'main doors'), they create the atmosphere of a school in which these messages reflect the strongest discourses in place and the 'presence or absence of particular languages' perpetuate the linguistic status of these languages in this context (Brown, 2012, p. 282). Specifically, the functions of the signs serve five functions of language (i.e., regulatory, interactional, personal, imaginative and representational). Representational signs make up the largest portion of the signs in the classroom wings (i.e., GBP and EMP), whereas regulatory signs are the most numerous in the common areas (Chart 2). Of note, there are over twice as many representational signs in the GBP classroom wing (28) as in the EMP classroom wing (13) or common areas (12). These purposes, intended audiences and language functions reveal the ways of thinking (i.e., discourses in place) that influence all decision making behind the sign making practices in the GBP. 
Chart 2. Sign function by location

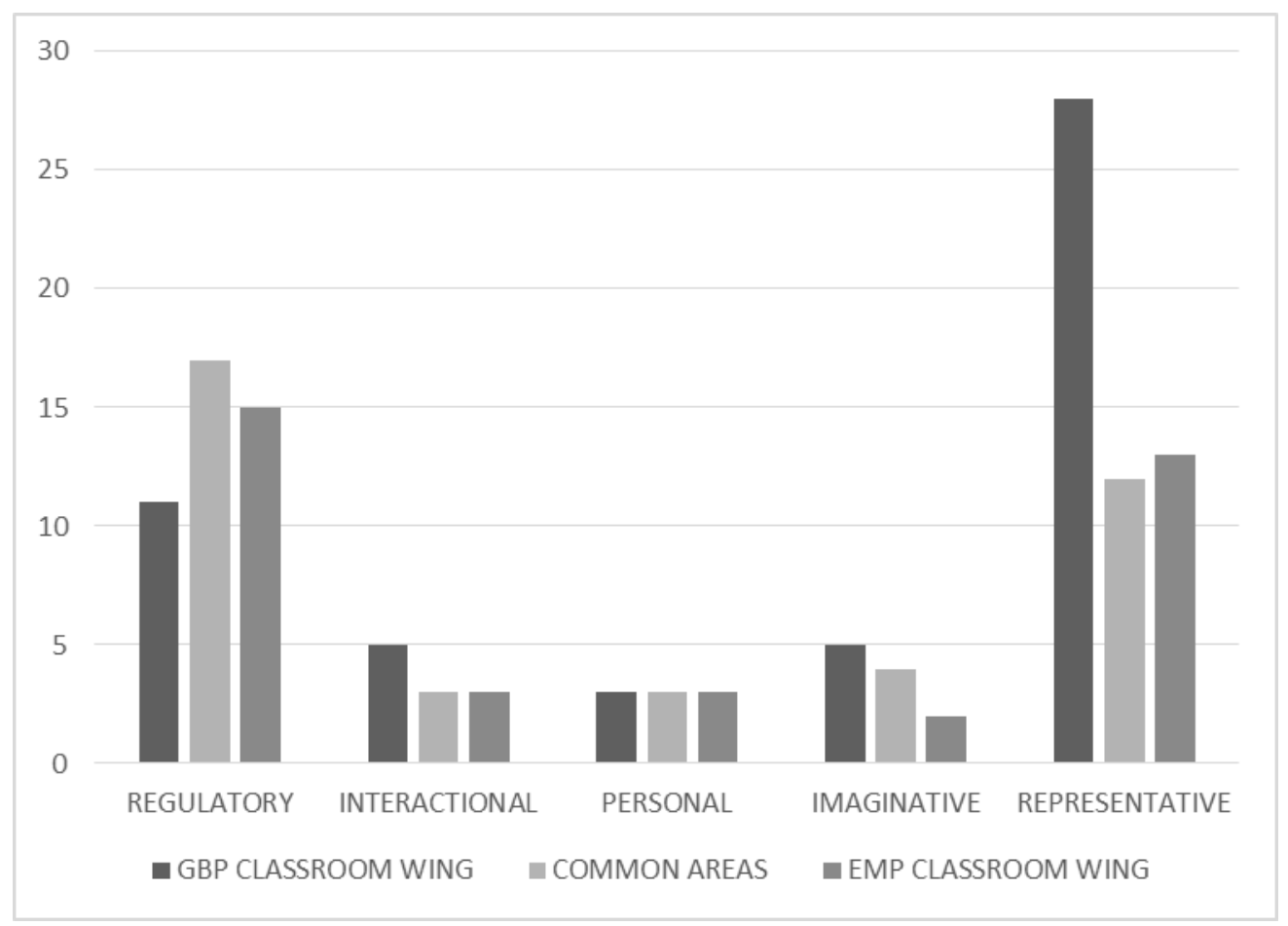

Selected signs illustrate how these three elements (historical body, interaction order, discourses in place) come together in nexus of practice constrained in responsibility and reach. These reveal how teachers as sign makers are constrained within the nexus of practice of sign making by what they perceive as their responsibility toward the promotion of bilingualism as well as their perception of the reach of the GBP within the larger context of the school.

\section{Responsibility}

The focus group data reveal that within the GBP, responsibility for sign making falls primarily to teachers. The action of creating and posting signs demonstrates the responsibility for the promotion of German-English bilingualism. The analysis reveals that they are constrained in their responsibility to promote bilingualism in their role as sign makers.

The one permanent top-down bilingual signs found in the GBP classroom wing was initiated and funded by the school administrators. The sign is made of two coloured hard plastic 
plates with engraved lettering and glued permanently to vertical surfaces. These door labels found at the end of the German wing (Figure 1) were created when the German Bilingual Program was first established in the school. The door labels serve a representational function in promoting the bilingualism of the GBP wing because they are neither instrumental (i.e., necessary for ensuring students go in and out) nor regulatory (directing the flow of foot traffic through the doors as in a busy restaurant). The choice of vocabulary contributes to this function by equating the German words for entrance (Eingang) and exit (Ausgang) with the high frequency English words in and out. No other doors in the school are marked with such signs.



Figure 1 Bilingual Door Labels

The teachers themselves only place top-down signs they receive from outside organizations, such as the poster from the Zentralstelle für das Auslandsschulwesen (German Central Agency for Schools Abroad) (Figure 2). This poster also serves a representational 
function, promoting German-English bilingualism by providing an example of authentic German. Within the nexus of practice of sign making, teachers perceive that their sign making practices are constrained to posters from outside agencies when it comes to top-down signs.

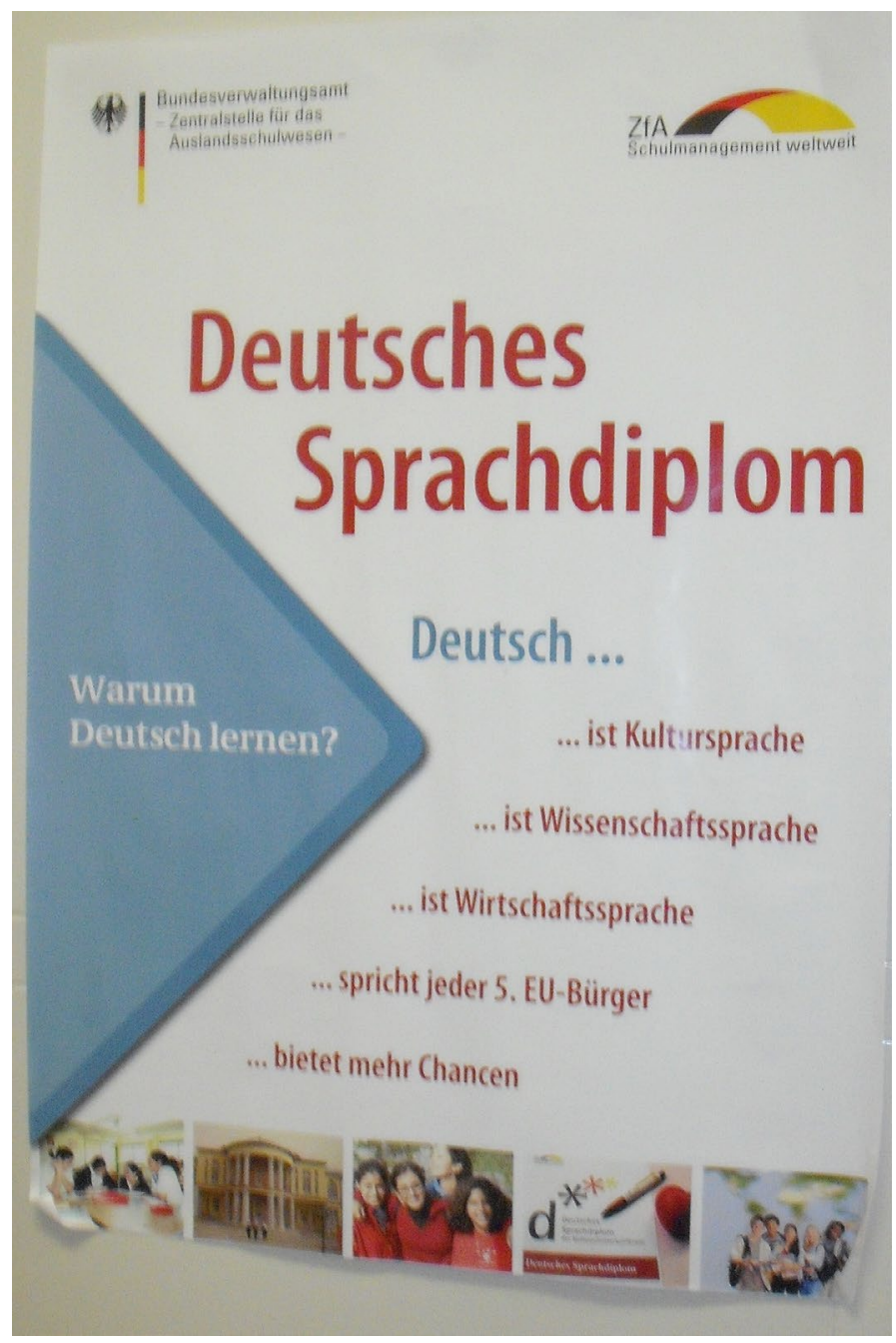

Figure 2 Poster from Outside Agency

Teachers are able to express the discourse in place of the promotion of German-English bilingualism through their bottom-down sign making, satisfying themselves with 'homemade environmental print' (Giles \& Tunks, 2010, p. 25). GBP teachers created 34 out of 58 bottom up signs in the combined GBP wing and common areas of which nine are German-only and three are bilingual. They create German-only or bilingual labels for student work that appear on 
bulletin boards outside of their classrooms (Figure 3). As revealed in the focus group, these signs are aimed not only at students, but also at parents who will visit the school for the Annual Open House in January, which took place just prior to the photographing of this linguistic landscape. These teacher-made labels combine with student work to create bulletin boards as representational signs that promote German-English bilingualism.

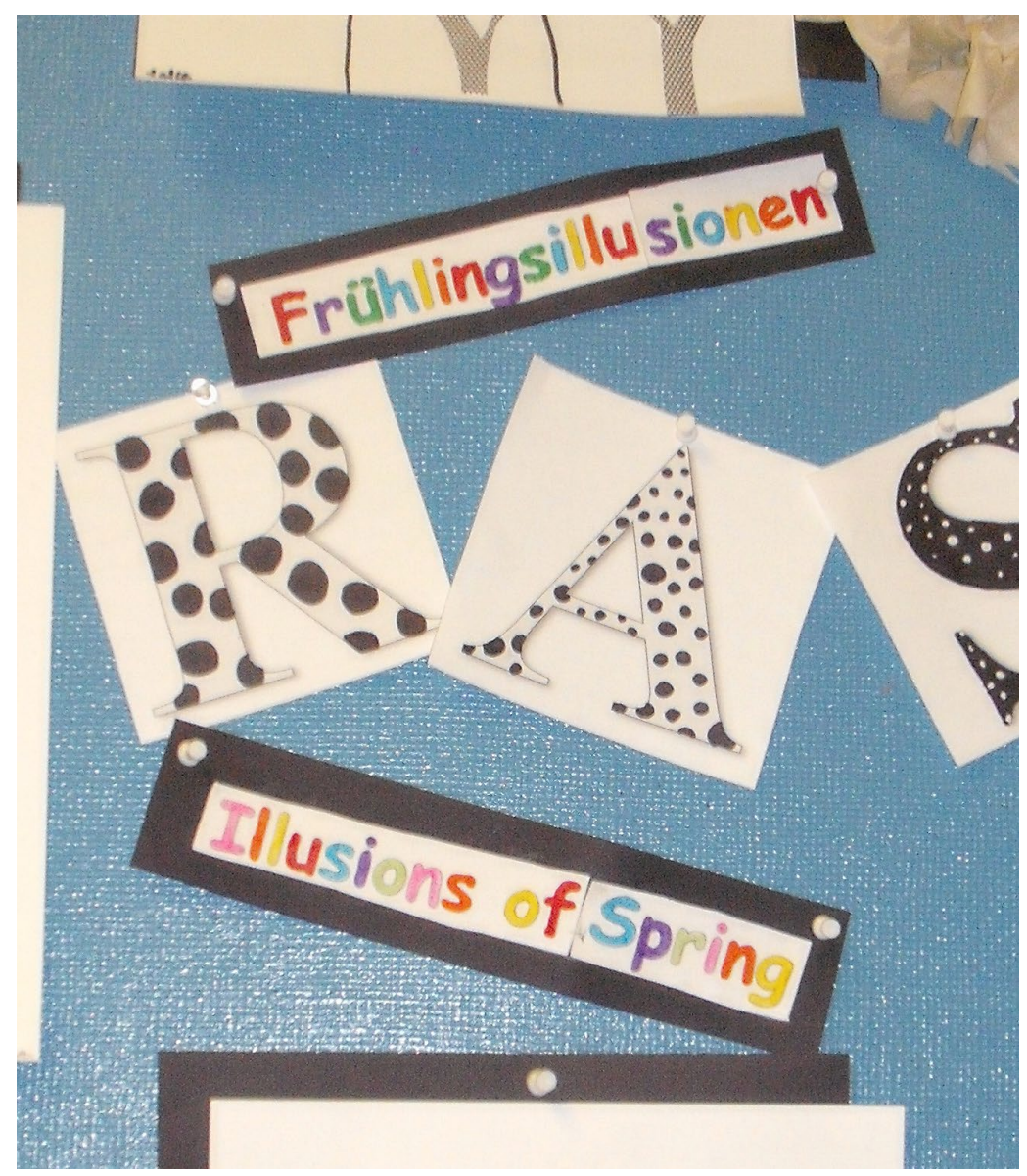

Figure 3 Bilingual Labels for Class Work

Most of the social actors with the German Bilingual Program do not carry the responsibility to create German or bilingual signs. In the nexus of practice around sign making, teachers, who are the social actors primarily, if not solely, responsible for the promotion of German-English bilingualism in the linguistic landscape, are the primary creators of such signs, They are constrained in fulfilling what they see as their responsibility by their lack of access to 
funds to commission permanent top-down signs and are therefore limited to low cost bottom-up signs. In the linguistic landscape of the GBP, responsibility for promoting German-English bilingualism is constrained to teacher-made signs.

\section{Reach}

The other area in which constraints affects sign making practices in the GBP is reach. Reach refers to the degree to which the nexus of practice around sign making in the GBP extend the discourse of bilingualism promotion beyond the physical space that the GBP occupies in the school. The reach of sign making practices can be understood by figuratively following the path students from the GBP wing take through the school to where they exit through the main doors and into the world outside of the classroom.

German Bilingual Program students spend the bulk of their time within the wing of the school where the GBP classrooms are located. Here the promotion of German-English bilingualism discourse is very apparent. Five of seven bilingual signs (four of which are representational) and 11 of 13 monolingual German signs (nine of which are representational) are found in this physical space. In addition, bulletin boards outside of classroom contain additional bilingual and monolingual German components (Figure 4). 


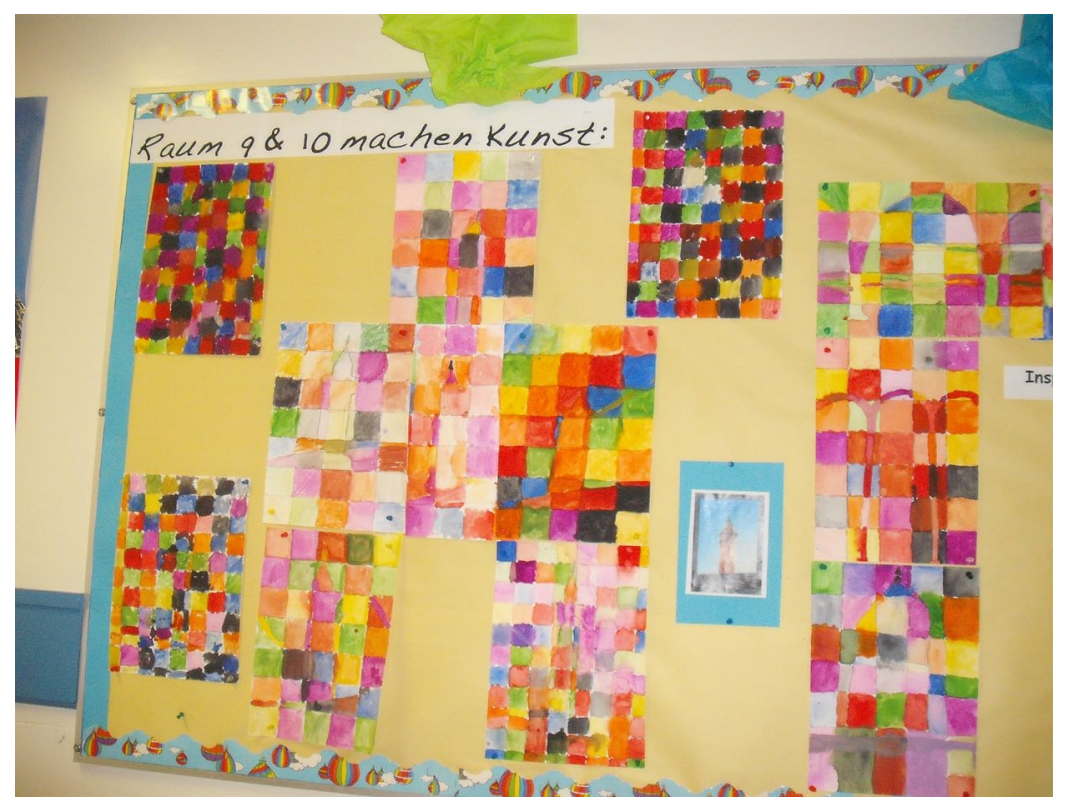

Figure 4 Bulletin Board Outside Classroom

Most teachers have one large bulletin board each. These bulletin boards are used to display student work and are changed with the highest frequency of all signs in the GBP. They demonstrate orderly placement in their confinement of student work to these finite spaces and the work they display reflect bilingualism on a teacher-chosen topic. The organic placement of offtheme student-produced creations or work from students of a different teacher is not in evidence. The borders of the bulletin boards serve as literal and figurative boundaries for the reach of each GBP class.

Between the GBP classroom wing and the front entry, the students pass 25 signs (23 monolingual English: 11 regulatory, four representational and one interactional; and two monolingual German, both representational). Several of these monolingual signs are created by school clubs, including numbers regulatory 'lights out' signs created by the Environmental Club (Figure 5). Placed in an orderly, strategic manner above almost every light switch, these signs carry the message that promotes energy conservation through regulation of electricity consumption. The absence of bilingual or German versions of these signs within the nexus of 
practice reflects the discourses in place that German-English bilingualism is not relevant to panProgram clubs. Ironically, some of the teachers who lead these clubs, as well as some of the student members, are from the GBP. While teachers from the focus group report that they are not expressly forbidden from asking some student club members, themselves GBP students, to create bilingual signs for the GBP wing, the teachers that lead these clubs act in these roles as representatives of the whole school and therefore default to the monolingual language choice characteristic of others who represent the whole school (i.e., school administrators and the school board). In other words, clubs are seen as part of the school and outside of the reach of discourses in place in the GBP. Even if the teachers who lead these clubs are GBP teachers, they do not consider using these signs as an opportunity to promote German English bilingualism.

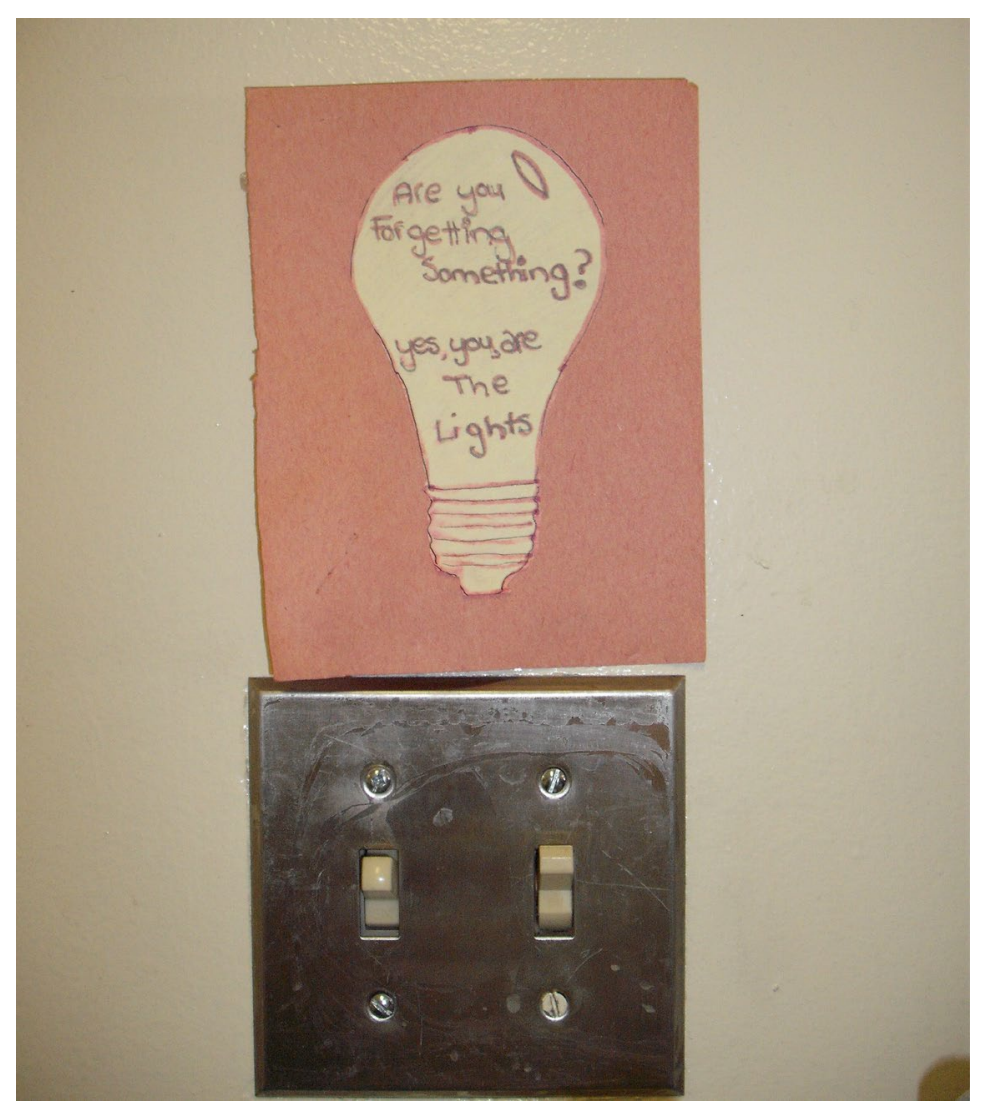

Figure 5 Lights Out Sign 
Within the entry, there are five signs, only one of which is bilingual (Figure 6). This bilingual sign is the only sign within the entrance way that indicates languages other than English have a place in this school. Placed beside a monolingual English sign indicating where visitors are allowed to park, the orderly placement of this sign communicates the regulatory message that the orderly behaviour of school visitors is of high importance (the removal of shoes upon entry). The presence of one bilingual sign and the absence of a representational bilingual welcome sign reveals the constraints upon the reach of the GBP within the nexus of practice.

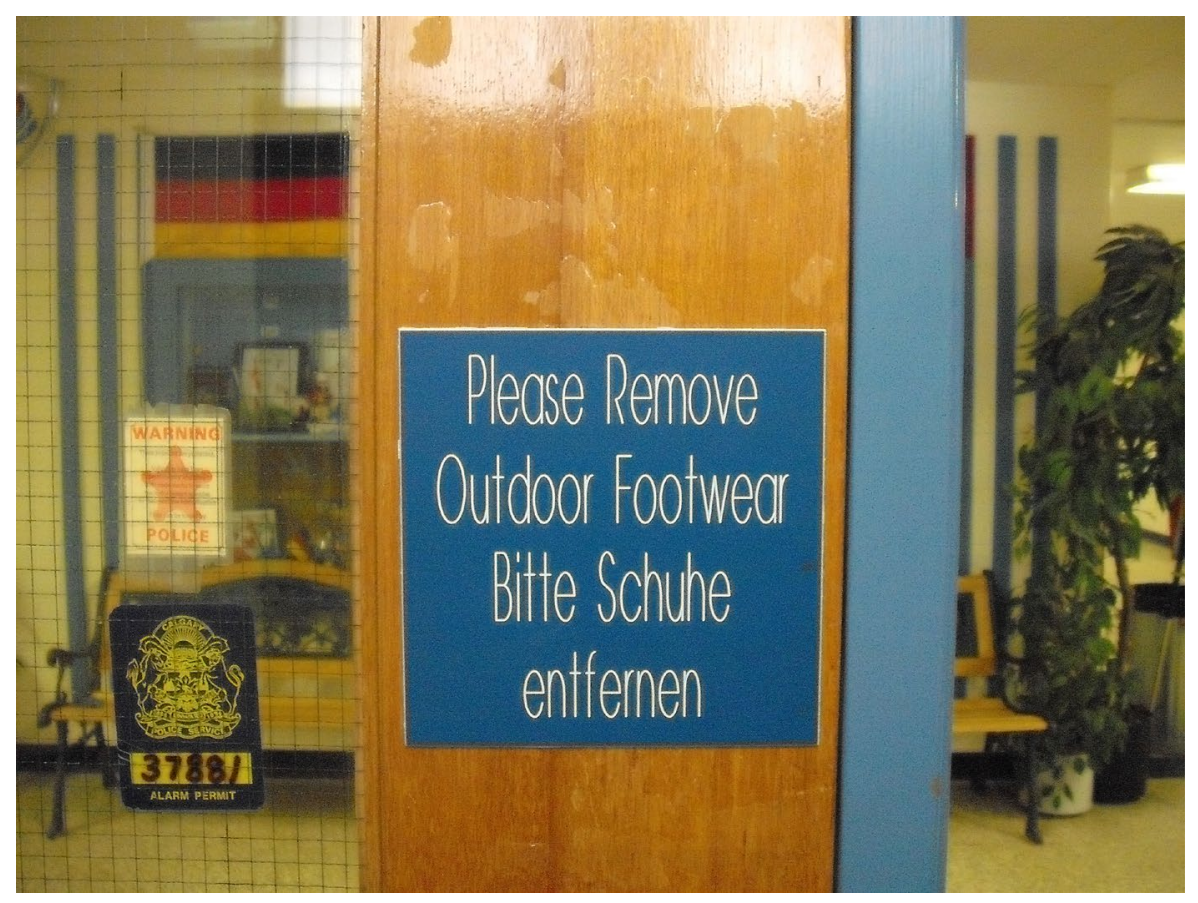

Figure 6 Shoe Removal Sign

On the outside of the school, a custom-made vinyl banner points to the presence of German within the school through the use of the word 'Deutsch' for German ${ }^{6}$. As the only token in the linguistic landscape of an outdoor sign with any language other than English sign, this banner stands out as an anomaly. It deviates from the typical signs of the school board because it is a vinyl banner and therefore more temporary in nature than the metal commercial signs on the outside of the school. It contains a personal message of pride for the existence of the GBP within 
the school, in contrast to the three representational signs and the remaining regulatory signs, all in English. The distribution of signs by location within the nexus of practice demonstrates that German-English and monolingual German signs are few in number outside of the designated GBP classroom wing of the school. As students leave the GBP classroom wing, the reach of discourse of German-English bilingualism dissipates to a few isolated tokens.

The constraints upon the reach of the GBP within the nexus of practice of sign making result in the limiting of German-English bilingualism and its promotion to the very area in which the social actors are most convinced of its value. Beyond the GBP classroom, visitors or students outside of the GBP encounter few signs that use both languages in a meaningful manner and GBP students are likely to conclude that the compartmentalization of the use of these languages together is indicative of a lower status of bilingualism within and outside of the school than within the GBP wing itself.

In the nexus of practice around sign making, the constraints of responsibility and reach are intertwined. Teachers, as the primary social actors who promote German-English bilingualism, lack responsibility for the budget to create top-down signs and the reach of their sign making is limited to bottom-up signs they make for use within the GBP. While these constraints affect teachers the most, they impact the nexus of practice of sign making in the German Bilingual Program for all social actors.

\section{Conclusion}

The nexus of practice around sign making provides evidence of the existence of the German Bilingual Program within the school's linguistic landscape; however, the majority of the signs are English-only and bottom-up and do not promote German-English bilingualism. The nexus analysis reveals that a) teachers are the primary creators of signs that promote German-English 
bilingualism; b) not all signs are subject to orderly placement and c) the promotion of bilingualism is only one of several discourses in place. In addition, teachers as sign makers are constrained in the responsibility outlined and the reach of German-English bilingualism within the school is limited to the GBP wing, with the exception of a few signs.

This examination of the linguistic landscape of a German Bilingual using nexus analysis makes an important contribution to our understanding of schools as unique linguistic landscapes. This study reveals the nexus of practice of school linguistic landscapes as subject to the historical body of numerous sign makers and an interaction order which exhibits aspects of orderly placement as well as organic proliferation. The discourses in place cycle around various pedagogical messages and are expressed via five functions of language. In fulfilling their responsibilities as sign makers, the social actors negotiate these various discourses and sometimes perceive that the promotion of bilingualism cannot coexist with the promotion of other discourses. Additionally, there are constraints upon the reach of the Program which result in little purposeful bilingual sign making beyond the GBP classroom wing. Responsibility and reach constrain the nexus of practice of sign making in its promotion of bilingualism.

The constraints revealed within the nexus of practice provide the basis for the recommendations arising from this study. Scollon and Scollon (2004) encourage change to arise from the nexus analysis. As change I would advocate addressing the constraints on the sign making practices. This involves educators:

(1) explicitly targeting the promotion of German-English bilingualism through the conscious use of bottom-up signage;

(2) encouraging GBP student members of school clubs to draw upon their linguistic resources to create bilingual signs; and 
(3) lobbying for the allocation of funds to top-down sign making.

In doing so, the teachers, in their roles as primary sign makers, would redefine their responsibilities and extend the reach of the promotion of bilingualism. With these changes, the constraints that impact the sign making practices of all social actors within the GBP would be minimized.

\section{Directions for Future Research}

Linguistic landscape research in schools is an area of research ripe for expansion. As Brown (2012) notes, 'despite the centrality of schools in perpetuating and disrupting language ideologies, linguistic landscape research has yet to focus extensively on school buildings as a key site for inquiry' (p. 282). Additionally, nexus analysis provides a methodology for inquiring into the ways of being, doing and thinking behind each sign. Just as this inquiry into the decision making behind signage was able to reveal the constraints upon responsibility and reach, future linguistic landscape research would be strengthened by the inclusion of the voices of the sign makers rather than reliance upon the strength of interpretations based on characteristics of the sign alone.

Future research exploring the nexus of practice of sign making in schools would profit from additional investigation of bilingual education internationally that promotes official languages (e.g., Immersion programs in Canada) as well as those promoting other non-official languages. This research could reveal additional constraints as well as additional discourses around the status and role of these languages in the schools and the lives of the students. In seeking to expand linguistic landscape research to interrogate the decision making behind sign making practices, future research would benefit from the inclusion of policy maker or student voices in the exploration of ways of being (i.e., historical body), opening it up to new discourses 
in place and potentially unique aspects of the interaction order that have an impact on the nexus of practice. In addition, the investigation could be expanded to include the insides of classrooms, comparing the discourses and constraints that impact them to those outside of the classrooms.

Dagenais et. al. (2008), comment on the observations children make about the linguistic landscape of their communities noting that, 'as children begin to move around their communities, interact with others and learn to read the signs that surround them, they attribute meaning to the public/authoritative discourses of their cities' (p. 256). In the same way, these children move about their schools and draw conclusions about the relative importance of the languages in the signs around them. This paper documents what children in one German Bilingual Program see in moving about their school, which signs promote the bilingualism of the Program and how constraints upon the responsibility of teachers and the reach of the Program affect sign making practices. Schools, especially those offering bilingual education, are indeed sites where languages come together, and analysis of the linguistic landscape illustrates how signs are used by their various creators, to send explicit and implicit messages about the status of language(s) through their distribution and use on signs. Combining linguistic landscape analysis with nexus analysis reveals that the linguistic landscape of a Bilingual Program are complex due to multiple sign creators, working within a given interaction order to create signs for many different purposes; however, the degree to which bilingualism is promoted is limited by constraints upon the responsibility of the social actors and the reach of the Program. 


\section{Acknowledgements}

I would like to thank Dr. Mary Grantham O’Brien for her support in this research, Dr. Francis

Hult for his comments on an earlier draft of this paper, Shannon Ryland and Jeanette Piddington for formulating a snappy title.

\section{Funding}

This work was supported by the Social Sciences and Humanities Research Council of Canada

[Award No. 767-2009-1535].

\section{Notes}

${ }^{1}$ In Canada, children enter the public school system at Kindergarten or first grade. In western Canada, Kindergarten is optional and children may enter when they are four years old, if their fifth birthday is before the end of December of that school year, with the exception of Alberta, where that birthday must be before the end of February of the school year. First grade is compulsory and may be entered as early as age 5 and no later than age 7 .

${ }^{2}$ In Canada, the term 'public school' refers to schools that receive $100 \%$ funding from the provincial government.

${ }^{3}$ I served as both moderator and note taker. In hindsight, I acknowledge that a separate note taker would have been able to record additional data that would have lent the teachers a stronger voice in this study.

${ }^{4}$ Two signs contained no text and were removed from the analysis: one bulletin board with student work but no accompanying text found in the English-medium program and one "dogs not allowed" sign outside on the outside of the school.

${ }^{5}$ Provincial fire code allows for the placement of combustible student artwork in hallways, provided it does not exceed $20 \%$ of the wall surface.

${ }^{6}$ In compliance with the confidentiality clause in my ethics agreement with the school board, I cannot provide a picture of this banner as it uniquely identifies the school board and school. 


\section{References}

Blackledge, A., \& Creese, A. (2010). Multilingualism: A critical perspective. London: Continuum.

Boudreau, A., \& Dubois, L. (2005). L'affichage à Moncton: Miroir ou masque? Revue de l'Université de Moncton, 36(1), 185-217.

Brown, K. (2012). The linguistic landscape of educational spaces: Language revitalization and schools in southeastern Estonia. In D. Gorter, H. Marten \& L. Van Mensel (Eds.), Minority languages in the linguistic landscape (pp. 281-298). New York: Palgrave Macmillan.

Cenoz, J., \& Gorter, D. (2006). Linguistic landscape and minority languages. International Journal of Multilingualism, 3(1), 67-80.

Cenoz, J., \& Gorter, D. (2008). The linguistic landscape as an additional source of input in second language acquisition. International Review of Applied Linguistics, 46, 267-287. doi: 10.1515/IRAL.2008.012

Cummins, J. (2005). A proposal for action: Strategies for recognizing heritage language competence as a learning resource within the mainstream classroom. Modern Language Journal, 89(4), 585-592.

Cummins, J., \& Early, M. (2011). Identity texts: The collaborative creation of power in multilingual schools. Stoke on Trentham: Trentham Books.

Curtin, M. (2009). Languages on display: Indexical signs, identities and the linguistic landscape of Taipei. In E. Shohamy \& D. Gorter (Eds.), Linguistic landscape: Expanding the scenery (pp. 221-237). London: Routledge.

Dagenais, D., Moore, D., Sabatier, C., Lamarre, P., \& Armand, F. (2008). Linguistic landscape and language awareness. In E. Shohamy \& D. Gorter (Eds.), Linguistic landscape: Expanding the scenery (pp. 253-269). New York: Routledge.

Eaton, S. E. (2005). 101 ways to market your language program: A practical guide for language schools and programs (2nd. ed.). Calgary: Eaton International Consulting Inc.

Genesee, F., \& Gándara, P. (1999). Bilingual education programs: A cross-national perspective. Journal of Social Issues, 55(4), 665-685.

Giles, R. M., \& Tunks, K. W. (2010). Children write their world: Environmental print as a teaching tool. Dimensions of Early Childhood, 38(3), 23-29.

Gorter, D. (2006). Introduction: The study of linguistic landscape as a new approach to multilingualism. International Journal of Multilingualism, 3(1), 1-6.

Hult, F. M. (2009). Language ecology and linguistic landscape analysis. In E. Shohamy \& D. Gorter (Eds.), Linguistic landscape: Expanding the scenery (pp. 88-104). London: Routledge.

Kramsch, C., \& Steffensen, S. V. (2008). Ecological perspectives on second language acquisition and socialization. In N. Hornberger (Ed.), Encyclopedia of Language and Education (pp. 17-28). Netherlands: Springer.

Lai, Mee Ling (2013). Linguistic landscape in Hong Kong after the change in sovereignity. Interational Journal of Multilingualism, 10 (3), 251-272. doi: 10.1080/14790718.2012.708036

Landry, R., \& Bourhis, R. (1997). Linguistic landscape and ethnolinguistic vitality: An empirical study. Journal of Language and Social Psychology, 16(1), 23-49. doi:

10.1177/0261927X970161002 
Moore, D. (2010). Multilingual literacies and third script acquisition: Young Chinese children in French immersion in Vancouver, Canada. International Journal of Multilingualism, 7(4), 322-342.

Morgan, B. (2004). Teacher identity as pedagogy: Towards a field-internal conceptualisation in bilingual and second language education. International Journal of Bilingual Education and Bilingualism, 7(2-3).

Pietikäinen, S., \& Kelly-Holmes, H. (2011). The local political economy of languages in a Sami tourism destination: Authenticity and mobility in the labelling of souvenirs. Journal of Sociolinguistics, 15(3), 323-346.

Pietikäinen, S., Lane, P., Salo, H., \& Laihiala-Kankainen, S. (2011). Frozen actions in the Arctic linguistic landscape: a nexus analysis of language processes in visual space. International Journal of Multilingualism, 8(4), 277-298. doi: http://dx.doi.org/10.1080/14790718.2011.555553

Prior, J. (2009). Environmental print: Real-world early reading. Dimensions of Early Childhood, 37(1), 9-13.

Prokop, M. (2007). A history of Alberta's German-speaking communities (Vol. 1). Okotoks: Manfred Prokop.

Reyes, I., \& Azuara, P. (2008). Emergent biliteracy in young Mexican immigrant children. Reading Research Quarterly, 43(4), 374-398. doi: 10.1598/RRQ.43.4.4

Sayer, P. (2009). Using the linguistic landscape as a pedagogical resource. ELT Journal, 64(2), 143-154. doi: 10.1093/elt/ccp051

Scollon, R., \& Scollon, S. W. (2004). Nexus analysis: Discourse and the emerging internet. London: Routledge.

Shohamy, E. (2006). Language policy: Hidden agendas and new approaches. London: Routledge.

Shohamy, E., Ben-Rafael, E., \& Barni, M. (2010). Introduction. In E. Shohamy, E. Ben-Rafael \& M. Barni (Eds.), Linguistic landscape in the city. Clevedon: Multilingual Matters.

Shohamy, E., \& Waksman, S. (2009). Linguistic landscape as an ecological arena: Modalities, meanings, negotiations, education. In E. Shohamy \& D. Gorter (Eds.), Linguistic landscape: Expanding the scenery (pp. 313-331). London: Routledge.

Swain, M., \& Lapkin, S. (2005). The evolving sociopolitical context of immersion education in Canada: Some implications for program development. International Journal of Applied Linguistics, 15(2), 169-186. doi: DOI: 10.1111/j.1473-4192.2005.00086.x

Tavares, A. (2000). From heritage to international languages: Globalism and western canadian trends in heritage language education. Canadian Ethnic Studies, 32(1), 156-171.

Wu, J., \& Bilash, O. (2000). Bilingual education in practice: A multifunctional model of minority language programs in Western Canada. Paper presented at the Hawaii International Conference on Education, Honolulu, Hawaii. 
Dressler 2015 


\section{Figure captions}

Figure 1. Bilingual door labels

Figure 2. Poster from outside agency

Figure 3. Bilingual labels for student work posted to a teacher bulletin board

Figure 4. Bulletin board

Figure 5. Lights Out signs

Figure 6. Shoe removal sign 